\title{
Los Regidores del Concejo de Lorca. Sus Ordenanzas y Evolución (1399-1509)
}

\author{
Francisco de Asis Veas arteseros \\ Angel LUIS Molina Molina *
}

Terminada la rebelión musulmana de 1264 y vuelto el Reino de Murcia a la soberanía castellana, Alfonso $X$ inicia una profunda remodelación del territorio, comenzando por tomar las medidas conducentes a asegurar el control efectivo y evitar posibles, aunque muy poco probables, sorpresas e iniciando la organización gubernamental de las poblaciones del adelantamiento. Dentro de este marco, en 1271 , el rey de Castilla otorgó un privilegio por el que concedía a la ciudad de Lorca el Fuero de Córdoba ${ }^{1}$, creando de esta manera un esquema concejil integrado por juez, alcaldes, mayordomo y escribano, elegidos por los vecinos de las parroquias en las que se encontraba compartimentada la población ${ }^{2}$, entre aquellas personas que fuesen "convenibles» para el cargo, cuyo mandato sería de un año, comenzando a contar desde el día de San Juan Bautista hasta el 23 de junio del año siguiente, fecha en que serían renovados todos los cargos.

* Universidad de Murcia.

1 1271-VIII-20, Murcia. Pub. J. TorRes FonTEs: «Fueros y Privilegios de Alfonso $X$ el Sabio al Reino de Murcia", Colección de Documentos para Historia del Reino de Murcia, III. Murcia 1973. Doc. CXIV.

${ }^{2}$ Sobre las colaciones o parroquias Vid. M. C. CARLE, «Del concejo medieval castellano-leonés", Instituto de Historia de España, Buenos Aires 1968, p. 122. También, sobre este aspecto y lo referente a oficios municipales y su elección, J. M. GaRcla MaRín: El oficio público en Castilla durante la Baja Edad Media, Madrid 1987, págs. 154-166. 
Se trata de un concejo en el que los vecinos de la localidad participan activamente en el gobierno local, asistiendo a las reuniones y adoptando los acuerdos que deberían ser ejecutados por los oficiales. Un organigrama reducido, adecuado a las necesidades de la población, que sería punto de arranque para las futuras transformaciones que sufriría el gobierno municipal lorquino.

\section{EL REGIMIENTO DE 1399}

Bastante tiempo permaneció vigente el régimen municipal alfonsino, ya que, pasado más de un siglo, Lorca se gobernaba "por conçejos generales" ${ }^{3}$. Pero este sistema que sería válido en los primeros tiempos, no lo sería tanto en aquellos otros en los que se inicia una política monárquica de intervencionismo en la esfera municipal, iniciada por Alfonso $\mathrm{XI}$, y que a Lorca le va a afectar, tiempo más tarde, como consecuencia de la división política del adelantamiento a fines del siglo XIV.

En efecto, en 1399 todo va a cambiar, ya que Enrique III se mostró firmemente resuelto a terminar con los conflictos existentes en la ciudad de Murcia, entonces en manos de los Manuel que habían expulsado de la ciudad al Adelantado, Alfonso Yáñez Fajardo, y a sus seguidores ${ }^{4}$, y cuyas secuelas se extendían por todo el territorio murciano. El monarca decidió otorgar plenos poderes a Ruy López de Dávalos, condestable de Castilla, para que viajase a la ciudad y reino de Murcia con objeto de acabar con tal situación e imponer el orden y la autoridad del rey ${ }^{5}$.

Cumpliendo las órdenes de Enrique III, el condestable, tras pacificar la capital del adelantamiento, llegó a Lorca en un día indeterminado que

${ }^{3}$ Apéndice Documental I.

${ }^{4}$ Lorca permanecerá al lado de Yáñez Fajardo. F. VEAS ARTESEROS: "Intervención de Lorca en la lucha entre Manueles y Fajardos en 1391 y 1395", Miscelánea Medieval Murciana, (MMM) VII. Murcia 1981, págs. 147-157. Sobre la contienda, M. LI. MARTínez CARRILLo: Revolución urbana y autoridad monárquica en Murcia durante la Baja Edad Media (1395-1420), Murcia 1980, págs. 133-146, y, especialmente, de la misma autora, Manueles y Fajardos. La Crisis bajomedieval en Murcia, Murcia 1985, págs. 126-151 y 228-248.

${ }_{5}^{5}$ El 15 y 20 de octubre se encontraba en Murcia, desde donde viajó a Cartagena y Lorca, lugares de los que regresó el 23 , día en que el concejo murciano se preparaba para recibirlo. Marchó a la corte el día 5 de noviembre. M. LI. Martínez CarRillo: Revolución..., p. 148. 
puede situarse entre el 20 y el 23 de octubre, siendo su estancia en la ciudad no muy superior a las 24 horas. Corto espacio de tiempo para solventar todas las cuestiones, pero sí el suficiente como para dar las instrucciones necesarias que condujesen a un cambio en el sistema municipal, pues encontró que la población se regía por un concejo abierto y que cuando «los tales conçejos se fazian publicamente que auia muchos escandalos e males", derivados de la asistencia de los "conçejales... con los ofiçiales a los cabillos e conçejos", lo cual distaba mucho de encajar en el planteamiento del monarca castellano. La cuestión quedó solucionada cuando Ruy López nominó una relación de 36 vecinos que, como regidores, deberían gobernar la ciudad junto al resto de los oficiales. Este nuevo sistema municipal consistía en el nombramiento de seis personas pertenecientes a cada una de las seis parroquias en las que se encontraba dividida la población ${ }^{6}$, y cada año, por la festividad de San Juan Bautista, seis de ellos - uno de cada parroquia- ejercerían el cargo de regidores, cediendo el puesto al año siguiente a otros seis y así sucesivamente hasta completar el ciclo de seis años, terminado el cual cada parroquia procedía a una nueva elección de la que no quedaban excluidos los que habian ocupado el puesto anteriormente por la parroquia en cuestión ${ }^{7}$.

En realidad López Dávalos, llevado por un sentido uniformista, no hizo otra cosa sino imponer en Lorca, a menor escala, la misma reforma

${ }^{6}$ En estos momentos San Clemente, Santa María, San Juan, San Jorge, Santiago y San Mateo. Al erigirse, a mediados del $\mathrm{xV}$, la de San Pedro entrará en competencia electoral con la de San Clemente, por lo que los reyes ordenaron que, por ser las mencionadas parroquias «... tan pequeñas e de tan pocos vezinos no ay en ellas copio de tantas personas como ay en cada vna de las otras collaçiones para concurrir a la dicha eleçion e nonbramiento... de aqui adelante, las dichas collaçiones de San Pedro e San Clemente sean avidas por vna collaçion en quanto atañe o atañare a la dicha eleçion de los dichos ofiçios». Apéndice Documental V. Los regidores Rodrigo Castejón, el mozo, y Juan Jiménez de Guevara lo eran por ambas parroquias en 1482 y 1489 . AML A.C. $1482-83$ y 1489-90 sesiones del 29-VI-1482 y $29-\mathrm{VI}-1489$.

7 Apéndice Documental VI. La falta de Actas Capitulares correlativas impide conocer la secuencia cronológica, pero de la consulta a los Documentos que se conservan se puede afirmar que era frecuente la nominación de los anteriores, así Fernán Pérez de Tudela fue regidor del año de 1440-41 y 1475-76, y de los 36 , es decir, electo cuando le llegase el turno, en 1464-65; Gil Martín de Pareja fue del año por la parroquia de San Jorge en 147879, 1488-89, 1495-96 y 1503-04, y de los 36 en 1489-90; Rodrigo Castejón, el viejo, regidor por la parroquia de San Juan, fue del año en 1464-65 y 1482-83; Juan García de Alcaraz, hijo de Sancho García, por la parroquia de Santiago, fue regidor del año en 1464-65, y 1482-1483, y de los 36 en 1478-79 y 1489-90. AML A.C. 1475-76, sesión del 9-1-1476; Documentos del siglo XV, Núm. 27; A.C. 1489-90, sesiones del 29-VI-1489 y 8-VIII-1489; Censos 1495, 5-VII-1495; A.C. 1503-04, sesión del 29-VI-1503; A.C. 1482-83, sesión del 29-VI-1482, y A.C. $1489-90$, sesiones del 29-VI-1489 y $17-11$ I-1490. 
que había introducido en el regimiento murciano ${ }^{8}$. De esta manera el concejo de Alfonso $X$ desaparece $y$ es sustituido por otro integrado por los regidores y oficiales, con un fuerte intervencionismo regio y con escasa participación de la comunidad vecinal, ceñidas a las elecciones. Se introduce ahora en el gobierno municipal lorquino una institución hasta entonces desconocida, como era el regimiento ${ }^{9}$, cuyos integrantes a partir de ahora irán adquiriendo un creciente protagonismo en la vida municipal, hasta conformar un grupo hegemónico formado por los personajes más destacados de la población, que acabará imponiéndose en el concejo a base de acaparar atribuciones que abarcaban todos los aspectos de la vida ciudadana, tal y como lo pone de relieve el Profesor Cerda ${ }^{10}$.

1. Elección de oficiales.

2. Administración de las rentas y bienes del común, puesto éste que convirtió el oficio en una fuente de enriquecimiento codiciada por todos ellos.

3. Vigilancia y supervisión de las obras públicas de la ciudad, ayudados por los jurados.

4. Velar por la seguridad jurídica y vital de todos los vecinos sin excepción.

5. Poseían, junto a los alcaldes de la población, una facultad de tipo normativo, plasmada en forma de peticiones al rey,

${ }^{8}$ En Murcia se designaron 108 individuos de los que 18 regirían cada año hasta cubrir el ciclo de seis años, pero aquí al finalizar dicho ciclo volvían a ocupar el cargo los del primer turno. Por lo demás cabe pensar que la normativa reguladora establecida en Murcia fuese la misma que se impone en Lorca y los objetivos similares: continuidad en el gobierno municipal, respetando las ordenanzas de regidores de los años anteriores, rotación de los nombramientos, vacantes cubiertas por elección entre los vecinos de la parroquia a la que perteneciese el regimiento, aprobación de las ordenanzas por la mitad más uno de los regidores del año y obligatoriedad de presentar las cuentas anuales. M. LI. MARTínez CARRILLO: Revolución..., p. 102.

${ }^{9}$ Que sepamos el regimiento solamente existía en Murcia desde tiempos de Alfonso XI. J. TORRES FONTES: «El concejo murciano en el reinado de Alfonso Xl», Anuario de Historia del Derecho Español, XXIII. Madrid 1953, págs. 5-25.

$10 \mathrm{~J}$. Cerda Ruiz Funes: "Hombres buenos, jurados y regidores en los municipios castellanos de la Baja Edad Media", Estudios sobre instituciones jurídicas medievales de Murcia y su Reino, Murcia 1987, págs. 347-349. 
bandos ciudadanos, peticiones a cortes, aprobación de ordenanzas municipales, etc.

6. Elevación de protestas al rey por incumplimiento de éste o de sus oficiales de los fueros y privilegios de la ciudad.

7. Junto con los oficiales y jurados, los regidores eran los encargados del mantenimiento de la paz, defendiendo los intereses de la ciudad y el mejor servicio real.

Este conjunto de facultades ponía en manos de los regidores un dominio efectivo sobre la ciudad y sus recursos, lo que traía consigo el enriquecimiento económico y el encumbramiento social del individuo que ejercía el cargo. A partir de ahora las reuniones del concejo contarían con la presencia de los «seys regidores del año" y la de sus compañeros de nómina a quienes no les tocaba el turno del regimiento "de los treynta e seys" pero que sí podían participar en las deliberaciones y temas tratados en los ayuntamientos. El ejercicio del regimiento por unos y otros no presuponía la incompatibilidad con otros cargos municipales remunerados, algunos de los cuales quedaban reservados a un regidor de los $36{ }^{11}$.

Los regidores percibian un salario cuyo montante desconocemos en el momento de la instauración del régimen Dávalos y años posteriores, pero sí sabemos que, en 1490, era de 2.000 maravedís por el año en

11 Así sucede con el de alcalde de las primeras alzadas. AML A.C. 1475-76, sesión del 6-II-1476. Entre los regidores que ostentaron cargos podemos citar, entre otros, a Juan Bravo de Morata designado ejecutor del concejo en 1489; Martín de Cañizares, contador para el mismo año; Rodrigo Castejón, el viejo, oidor en 1482; Rodrigo Castejón, el mozo, ejecutor el mismo año; Gómez Fajardo, contador para dicho año; Juan Felices, contador en 1489, procurador síndico y juez de los alardes en 1503; Martín Fernández Piñero, contador en el mismo año; Juan García de Alcaraz procurador de la alquería de Albacete en 1489 y de la de Tercia en 1494; Mateo Alfonso, procurador de la de Albacete en 1494; Pedro Mellado, alcalde de las aguas en 1503; Martín de Molina, alcalde de las aguas en sustitución del fallecido regidor Pedro Leonés, el mozo, en 1489; el bachiller Alvaro Pérez de Briviesca, letrado concejil en 1503; Ramón Ponce, mayordomo en 1495; Juan Ponce de León, alcalde de las primeras alzadas, en 1476; y Alfonso Ponce de León, alguacil en 1475. AML A.C. $1489-90$, sesiones del 29-VI-1489, 30-VI-1489 y 11-VII-1489; A.C. 1482-83, sesión del 29-VI-1482; A.C. 1503-4, sesión del 29-VI-1503; A.C. 1494-95, sesión del 1-VII1494; A.C. 1485-76, sesión del 6-II-1476. 
que el individuo había ocupado el cargo de regidor ${ }^{12}$. Pero el interés personal y las ocupaciones extraconcejiles, motivaba el que la concurrencia a los ayuntamientos fuese escasa, de manera que la obligatoriedad de asistir a las reuniones ordinarias, celebradas los martes y sábados de cada semana, y a las extraordinarias cuando fuese necesario convocarlas, aunque aceptada por todos no se cumplía, por lo que el concejo ordenó que «el regidor o ofiçial del conçejo que ouiere de regyr... que esten residentes en el conçejo el día del sitio e ayuntamiento, so pena de treynta maravedis al que faltare e quel mayordomo se los descuente del salario" ${ }^{13}$, siempre que no hubiese causa justificada para la ausencia a juicio de los miembros del concejo.

A pesar de que los regidores procediesen «de todos los estados de la dicha çibdad", la realidad es que pronto van a predominar aquellos hidalgos y cuantiosos, obligados por su condición a mantener caballo y armas ${ }^{14}$, y poseedores de tierras y bienes del común a censo ${ }^{15}$. Pero,

12 AML Libro de Propios de 1490, fol. 6. La misma cantidad percibian en 1505. En Murcia, a partir de 1424 , los regidores vitalicios cobraban 1.500 maravedís anuales, cifra que aumentó a 2.000 en 1482. Cabe pensar que en Lorca la cifra salarial antes de 1490 fuese igual o inferior a la de los integrantes del regimiento murciano. M. C. VEAS ARTESEROS: La Hacienda concejil murciana en el siglo XV (1423-1482), Murcia 1988, págs. 1439-1471.

${ }^{13}$ AML Libro de Propios de 1490, fol. 7. A. L. Molina Molina: «Las Ordenanzas de Cabrero al concejo de Lorca (1490)". Cuadernos de Historia 10, Madrid 1983, p. 134. Las ausencias quedaban registradas haciendo una señal junto al nombre del ausente sin causa justificada, como sucedió con Juan García de Guevera, regidor del año por San Mateo, Alvaro Pérez de Briviesca, regidor del año por la de Santiago, y Juan Fernández de Ribavellosa, regidor del año por la de San Juan, todos en 1489. AML A.C. 1489-90, sesión del 3-XI-1489. Paliar la ausencia de regidores tiene como objetivo la instrucción dada por Isabel I al corregidor de Lorca para que se informase de la conveniencia de que la plaza se rigiese por 12 regidores anuales en lugar de los seis acostumbrados, pues «por cabsa que los dichos seys regidores son de todos los estados de la dicha çibdad e muchas vezes acaesçe que la mayor parte de los regidores van a atender en sus haziendas y en otras cosas fuera de la dicha çibdad, quedan muy pocos regidores para la regir y que por cabsa desto avyan fecho vna hordenança que como regian en la dicha çibdad cada año seys regidores rigesen doze". Facultaba al corregidor para que designase el número adecuado, siempre que no sobrepasasen la docena. Apéndice Documental VI.

${ }_{14}$ Obligación que el concejo recordará a los regidores como Fernán González de Gomariz, regidor del año por la parroquia de San Juan en 1478 y 1489, y de los 36 en 1465 , 1475 y 1490, quien, en 1475, ante los requerimientos de sus compañeros de consistorio, prometió adquirir un caballo en un plazo de cuatro meses, bajo pena de no hacerlo de 1.000 maravedís. AML A.C. 1489-90, sesión del 29-VI-1489. Documentos del siglo $\mathrm{xV}$, núm. 27. A.C. 1475-76, sesión del 7-XI-1475.

${ }_{15}$ Algunos de ellos tenían a censo unos lotes de tierra denominados asentes «que son pieças e tierras de pan llevar, que son del conçejo, que solian tener los cavalleros de la guerra que avia en esta çibdad». A. L. MolinA Molina: «Las Ordenanzas...,» p. 135. Pensamos que estos asentes pueden ser las tierras que para su mantenimiento fueron cedidas 
junto a la cuantía o no, la suficiencia del individuo era condición indispensable para ser regidor y de ello se preocupó Juan Cabrero, titular del corregimiento murciano entre 1487 y 1490 , al ordenar que las regidurías se cubriesen por personas «ydoneas e sufiçientes" y no por "parçialidad ni fauor", pues en tal caso los cargos de regidor y otros serían ocupados por personas de dudosa reputación ${ }^{16}$.

En cualquier caso, la entrada en el regimiento abría las puertas al individuo para la creación de una relación de intereses particulares, a veces abusivos ${ }^{17}$, que poco a poco irán abarcando a otros miembros de

por el concejo a los 60 caballeros no cuantiosos, establecidos en Lorca con carácter permanente y para cuya dotación Enrique III otorgó una cuantía de 30.000 maravedís. F. VEAS ARTESEROS: «Lorca, base militar murciana frente a Granada en el reino de Juan II (14061454)", MMM V. Murcia 1980: Apéndice Documental I. En 1490, desaparecido prácticamente el carácter fronterizo de Lorca, estos caballeros de guerra desaparecerán también, y las tierras por ellos ocupadas revierten al conçejo, quien las dará a censo. Juan Fernández de Ribavellosa pagaba de censo por dos de estos lotes de tierra que tenía en la «acequia del Pozo", uno de ellos de "fasta vn cafiz", 300 maravedís. Juan García de Guevara, regidor por San Mateo, abonaba al año 50 maravedís por un asente que tenía en el Cañarejo. Pedro Mellado disfrutaba de un asente en la «açequia del Pozo, de ocho fanegas de senbradura", por el que pagaba 345 maravedís al año. AML Libro de Propios de 1495, Asentes. Otros poseian, también a censo, bienes concejiles, así Martín de Molina que tenía el molino de los Arcos, compartido con sus hermanos Pedro y García, por importe de 25 maravedís al año, en 1490, igual cantidad pagaban los herederos de los tres hermanos cinco años después. Collado de Guevara poseía la torre «cabo la casa de Andres Garçia de Mula", por 10 maravedís anuales, en 1490 y la Torrecilla, por otros 10, en 1495. Martín de Cañizares, regidor por Santa María, pagaba 10 maravedís anuales, por la almazara que tenía compartida con Fernando de Zafra y los herederos de Guillamón Azor, y otros 10 por el solar de la cazacaya que afruenta con el huerto del tinte de Pedro Martinez» y con la torre de Martín de Morata de los Pozos, todo en 1490. Ramón Ponce, abonaba 10 maravedís anuales por el tinte que poseía "que era de Baeça», en 1495. AML Libro de Propios 1490 y 1495 , Censos de Casas y Torres.

${ }_{16}$ El corregidor reunió a todos los regidores lorquinos, en marzo de 1488 y les tomó juramento «e fizo obligar por cada mill doblas» por el que se comprometían a elegir al más capacitado cuando se produjese una vacante en el regimiento, alcaldía, juraduría, alguacilazgo u otro cargo concejil. Todo ello fue ratificado por los reyes en 1488-VI-3, Murcia. AML Cartas de los Reyes Católicos. Arm. 1. Pero a pesar de todo, había ocasiones en las que para el cargo de regidor, alcalde de la hermandad, mayordomo, jurados, etc., se elegían «por debdo o por favores o por parçialidades o otros respectos... a algunas personas ynabiles que no saben leer ny son abonados e que son algunos dellos ynfames", por lo que Juana I dispuso que tal elección recayese en personas «abiles e sufiçientes e de buena fama e conçiençia... y en quien concurren las calydades que las leyes de mys reynos disponen". 1508-XI-9, Sevilla AML Libro de Privilegios, fol. 129r-130r.

17 Tal es el caso del regidor Fernando Pérez de Tudela, regidor del año 1476, quien aprovechó su situación para mostrar una prepotencia desmedida para hacer oídos sordos a los requerimientos que le hizo el alarife Pedro de Mula, para que derribase una pared de su casa que estaba vencida y en peligro de desplomarse, por lo que el alarife no tuvo más remedio que acudir ante el concejo, exponer sus quejas y hacerles responsables, en caso 
su familia, dando lugar a la existencia de verdaderas dinastías de regidores pertenecientes a una misma familia, que irán alternándose en el ejercicio de cargos concejiles y llegarán a considerar el regimiento como algo patrimonial, fenómeno que viene favorecido, lo mismo que la perpetuación de las nominaciones resultantes de las elecciones parroquiales, modificadas en lo que se refiere a cobertura de vacantes ${ }^{18}$, por la influencia que determinadas familias o personas tenían en sus parroquias de residencia o relaciones de amistad o parentesco con miembros del grupo dirigente municipal ${ }^{19}$. Destacan dentro del regimiento los individuos pertenecientes a familias de alto nivel social y económico, que aportan un buen número de regidores, con activo protagonismo concejil y extraconcejil, como es el caso de los Fajardo ${ }^{20}$, Castejón ${ }^{21}$, Ponce de León ${ }^{22}$, Mellado ${ }^{23}$ y García de Alcaraz ${ }^{24}$.

de que no mandasen derribar el muro, del daño que pudiera seguirse del inminente derrumbe. AML A.C. 1475-76, sesión del 9-1-1476.

${ }^{18}$ En 1488 el sistema de elección una vez producida una vacante en los cargos de alcalde, alguacil, regidor, jurado o mayordomo, que se cubria antes por elección entre los vecinos de la parroquia, se modifica y pasará a ser realizada por el corregidor o su lugarteniente o bien un alcalde ordiriario «que tome secretamente de cada vn regidor, particularmente, juramento que declare las personas que oviere en la collaçion... para el tal ofiçio, e que declarados que declare que aquellos qual o quales sera o seran mas perteneçientes para el dicho ofiçio, e que asy declarado quel tal ofiçio sea dado al que toviere mas bozes de los regidores que asy ovieren jurado e declarado de elegir a los dichos ofiçios". Los reyes lo confirman, 1488-VII-17, Murcia. AML Libro II de Privilegios, fol. 134r-135v.

19 A pesar de la disposición concejil referente a que «qualquier de la collaçion que pidiere el tal ofiçio, ora para alcalde o alguazil o para regidor o jurado o mayordomo... que por aquel año quede ynabile e no le sea dado el tal ofiçio, ni el regimiento de la collaçion se lo puedan dar el tal ofiçio al tal ome que asy se yngiriere e pidiere el tal ofiçio...", confirmada por los reyes, Ibidem. Nota anterior, las presiones no escaseaban. En 1475 se produjo el fallecimiento del regidor por la parroquia de San Pedro, Antón Pérez de Panes, lo que debiera haber producido una votación entre los vecinos de la parroquia para proceder a cubrir la vacante, pero no fue así ya que los que se reunieron fueron los cinco restantes y presentaron al concejo a Juan de Guevara, hijo de Alfonso de Guevara y pariente del también regidor de dicha parroquia, Collado de Guevara. El concejo lo aceptó y tras prestar juramento ocupó el cargo. AMM A.C. 1475-76, sesión del 18-VII-1475. 
HACIA EL REGIMIENTO VITALICIO

La ordenanza de 1399 comenzó su andadura no exenta de dificultades, derivadas del descontento producido por la reducción de la participación ciudadana y el monopolio de los regidores que implicaba, que ya se manifestaron el 24 de junio de 1412, cuando, como estaba reglamentado, el concejo se reunió para proceder a la recepción y elección de los nuevos regidores y oficiales, "algunas personas desa dicha villa se alborotaron y levantaron diziendo que no consentian que obiese regidores e que los quitasen e que se movyo gran alboroto" ${ }^{25}$. La situación fue

${ }^{20}$ El comendador Gómez Fajardo era regidor por la parroquia de San Jorge en 1482, simultaneando dicho cargo con el de contador. AMM A.C. 1482-83, sesión del 29-VI-1482, de los 36 lo era en 1490. AMM A.C. 1489-90, sesión del 17-III-1490. Entre sus ocupaciones destaca el arriendo de uno de los molinos más concurridos de la ciudad como era el del "Rincón", por el que pagaba de censo at concejo 25 maravedís anuales. AML Libro de Propios, 1490 , fol. 5. Los servicios prestados a la ciudad, hicieron que fuese eximido de la alcabala y otros derechos que debía satisfacer por la venta de un buey, así como de la sisa. AML A.C. 1489-90, sesión del 8-IX-1489. Martín Fernández Fajardo, "El de la ceja blanca", era hijo del alcaide de Lorca, Alonso Fajardo "El Bravo" y María Piñero, hija de otro famoso alcaide lorquino, Martín Fernández Piñero «el del brazo arremangado". J. TORRES FONTES: «LOS Fajardo en los siglos XIV y XV», MMM, IV. Murcia 1978, p. 168. Fue alcaide de Huercal, en 1488, y Señor de Montealegre. F. VEAS ARTESEROS: «La cesión de Huércal y Overa a Lorca en 1488", Roel, 4. Albox 1983; Nota 15 y Apéndice Documental. Llegó a ser regidor perpetuo de Lorca, siendo sustituido a su muerte, en 1509, por Adrián Leonés. Apéndice Documental VII. Martín Fernández Piñero, al liamarse igual que el alcaide lorquino, pensamos que debe tratarse de algún familiar cercano, tal vez nieto. Ocupaba la alcaldía de la Hermandad en 1488. F. VEAS ARTESEROS: «La cesión...». Apéndice Documental; y el cargo de regidor del año en 1495, regidor y contador en 1503 y regidor de los 36 en 1490. AML Libro de Propios de 1495, Censos, A.C. 1503-4, sesión del 29-VI-1503 y A.C. 1489-90, sesiones del 11-1II-1490 y 17-III1490. Por lo que se refiere a Payo Fernández Piñero, en principio cabria pensar que era hermano del anterior, pero la cronología plantea de momento serias dudas que, aunque no impiden tal afirmación, sí permiten otras combinaciones, como la posibilidad de que fuera padre. Las únicas referencias que tenemos es que era regidor de los 36 desde 8-XIII-1464 a 2-V-1465. AML Documentos del siglo xV. Núm. 27. Su ausencia en documentos de años posteriores tal vez sea indicativa de su muerte, pero la falta de Actas Capitulares y otra documentación, no permite, por ahora, aventurar dato alguno.

${ }^{21}$ Rodrigo Castejón, el viejo, y, el mozo. Pensamos que padre e hijo, regidores de San Juan el primero y de San Pedro-San Clemente el segundo. AML Documentos del siglo XV núm. 27. A.C. 1482-83, sesión del 28-V/-1482. Caso similar es el de la familia Leonés a la que pertenecen Pedro Leonés, el viejo, Pedro Leonés, el mozo, y Adrián Leonés. El primero, regidor del año por la parroquia de Santa María en 1482 y 1495, procurador de la Alquería de Tercia y regidor de los 36 en 1490. AML A.C. 1482-83, sesión del 29-VI-1482; Libro de Propios 1495, Rentas, A.C. 1489-90, sesión del 29-VI-1490. El segundo fue regidor de los 36 y ejecutor del concejo en 1482 y de los 36 y alcalde de las aguas en 1489, 
atajada por Juan II al ratificar en todos sus extremos lo ordenado por Ruy López de Dávalos, según lo había confirmado Enrique III. De nuevo la carencia de fuentes documentales nos impide saber si se produjo algún intento más en este sentido, si tal hubo el resultado fue el mismo pues el sistema Dávalos seguía vigente a fines del siglo $\mathrm{xV}$.

\section{Lo que sí nos proporcionan los documentos son noticias referentes} a las intentonas «de algunos cavalleros e personas, vezinos de la dicha çibdad,... por se apoderar del regimiento e governaçion de la dicha çibdad... e de fazer los dichos regimyentos perpetuos e que sean catorze» ${ }^{26}$, es decir la reducción del número de regidores y la conversión

muriendo el 11 de julio de ese año. AML A.C. 1482-83, sesión del 29-VI-1482, A.C. 1489 90, sesión del 29-VI-1490. El tercero fue regidor vitalicio a partir de 1509.

${ }^{22}$ Alfonso ya era alguacil en 1475 y en 1503 regidor y contador. AML A.C. 1503-4, sesiones del 29-V|-1503 y 27-I-1504. Libro de Propios 1505, 4-IX-1505. Juan aparte del cargo de regidor de los 36 en 1465 y 1478, ocupó la alcaldía de las primeras alzadas en 1476 , fecha en que, como queda dicho, tal cargo quedó vinculado al regimiento de los 36 , y la alcaidía de la Mesta, en 1482. AML Documentos del siglo xV. Núm. 27, A.C. 1475-76, sesión del 6-II-1476, A.C. 1478-79, sesión del 20-VII-1478 y A.C. 1482-83, sesión del 29VI-1482.

${ }_{23}$ Juan Mellado es uno de los personajes más dinámicos de su época. Ya en 1475 fue nominado regidor del año por la parroquia de San Jorge, recibiendo al poco tiempo el cargo de oidor del concejo y haciendo frente, también ese año, a una orden de prisión dictada por el concejo contra él por "cambiar el pan en el Corral Rubio", cambio del que debió obtener buenos beneficios, pagando de pena por su ligereza 1.000 maravedís. Poseía una torre de la Puerta de la Judería, por la que, en 1490 pagaba de censo al concejo 81 maravedís, igual cantidad que cinco años más tarde pagaban sus herederos. En 1482 fue designado procurador de la Alquería de Albacete. Su nombre aparece asociado con el de otro personaje lorquino de este momento, el adalid Juan Mellado, de quien, en mayo de 1476 se dice que por los daños que había causado se le quitase el salario, las casas, las eras y que su mujer e hijos fuesen expulsados de la ciudad en un plazo de cuatro días. Sin lugar a dudas no se trata del mismo hombre, pues poco después el regidor Juan Mellado es enviado a Murcia, junto a otros colegas del regimiento para entrevistarse con el Adelantado. AML A.C. 1475-76, sesiones del 29-VI-1475, 18-VIII-1475, 24-VIII-1475, 28-V. 1476 y 22-Vl-1476. Documentos del siglo xv, núm. 27; Libro de Propios de 1490, Censos; Libro de Propios de 1495, Censos y Rentas. Familiares suyos eran Pedro Mellado, regidor de los 36 en 1490, regidor y alcalde de las aguas en 1503 y ejecutor en 1494. AML A.C. 1489-90, sesión del 11-III-1490; A.C. 1503-4, sesiones del 29-VI-1503 y 11-V-1504, y A.C. 1494-95, sesión del 25-VIII-1494, y Alfonso Mellado, regidor en 1503. A.C. 1503-4, sesión del 5-XII-1503.

${ }^{24}$ Juan García de Alcaraz, hijo de Bartolomé García, regidor de los 36 en 1465. AML Documentos del siglo $\mathrm{xv}$, núm. 27, del que no hemos encontrado referencias en documentos posteriores. Juan García de Alcaraz, hijo de Sancho García, regidor del año en 1465 y 1482 por la parroquia de Santiago, y de los 36 en 1478 y 1490, contador en 1482, procurador de la Alquería de Albacete en 1489 y de la de Tercia en 1494. AML Documentos del siglo xv. Núm. 27, A.C. 1482-83, sesión del 29-VI-1482; A.C. 1489-90, sesiones del 29-VI1489 y 17-III-1490 y A.C. 1494-95, sesión del 1-VII-1494. Gómez García de Alcaraz, regidor 
del cargo en vitalicio. Ahora la carta de los reyes confirmando la ordenanza de los 36 impidió la consumación del proyecto, pero se trataba de algo momentáneo pues en los planes de los soberanos entraba la modificación sustancial del regimiento lorquino, de manera que tan sólo un año después de esta confirmación ya se podía ver claramente que el final del camino que conducía a la creación de regidurías vitalicias estaba cerca, ya que, en 1478, Fernando $V$, compartiendo la opinión que, en nombre del concejo de Lorca, le expuso Juan Pardo, ordenó la reducción a 12 regidores y modificó el modo de elección existente, rompiendo el sistema representativo basado en la parroquia ${ }^{27}$.

La nueva revocación de esta medida y la consiguiente confirmación de la ordenanza de los 36 , se debió a una reacción «de algunos regidores de la dicha çibdad... nos hizieron saber como otros algunos regidores desa dicha çibdad yntentavan quebrantar los buenos vsos e costunbres della, queriendo mudar en otra sustançia los ofiçios de alcaldes e alguaziladgo e regimientos... E despues, estando yo, el rey, en la villa de Madrid, a suplicaçion de los dichos regidores que yntentaron quebrantar los dichos privilegios..., con relaçion no verdadera que sobre ello me fyzieron, mande dar e di vna mi carta... mudando la sustançia de los dichos privilegios" ${ }^{23}$. La división de los miembros del regimiento es pal-

de los 36 en 1490. A.C. 1489-90, sesión del 11-IIl-1490. Otro miembro de la familia, Alfonso García de Alcaraz, era escribano mayor del concejo.

${ }^{25}$ Apéndice Documental II.

${ }^{27}$ Apéndice Documental IV. En virtud de la orden real, producida una vacante de los 36 regidores de la ciudad, no se llevaría a cabo elección alguna, de manera que los regimientos que excediesen a 12 fuesen consumidos. Una vez llegado al número indicado comenzaría a tener vigencia la disposicién del monarca y entonces la vacante se cubriría mediante la elección, por parte de los regidores restantes y los oficiales, de dos individuos del cuerpo vecinal de la ciudad y no de parroquia alguna, y uno de los dos, por suerte, sería nombrado regidor de la ciudad. De la misma manera se modifica el nombramiento y elección de alcaldes, alguacil, jurados y mayordomo, que hasta entonces cada año pertenecían a una misma parroquia. Ahora se anula la referencia parroquial y los regidores procederán a la elección de dichos oficiales entre todo el vecindario, tomando para cada cargo dos candidatos uno de los cuales, por suerte, ocupará el puesto para el que fue escogido.

${ }_{26}$ Apéndice Documental III. En realidad se manifiesta en Lorca, tal vez con anterioridad a esta fecha, lo mismo que había sucedido en Murcia hacia 1420, cuando ya Alfonso Yáñez Fajardo, a pesar del juramento que había realizado de «no procurar quel regimiento desta dicha çibdad sea tornado perpetuo", influyó en Juan II para que modificase lo que Ruy López de Dávalos dejó ordenado. El resultado fue la reforma del regimiento murciano en 1424, merced a una carta del rey por la que designaba 16 regidores vitalicios. F. VEAS ARTESEROS: “Dinámica del concejo de Murcia (1420-1440): Los Regidores», MMM, IX. Murcia 1982 , p. 98.

${ }^{28}$ Apéndice Documental V. 
pable entre los partidarios del regimiento vitalicio, defendido por aquellos que tenian una posición más sólida y por tanto con mayores posibilidades de quedarse con el cargo, y los que, temerosos de perder la posición que tenían, deseaban a toda costa mantener la situación. Vano esfuerzo, pues con la venida de los reyes al reino de Murcia, con objeto de dirigir desde la frontera la campaña contra Granada de 1488, llevará consigo la orden al corregidor para que viese la conveniencia de reducir el número de regidores a $12^{29}$, cosa que Mosén Juan Cabrero pondrá en práctica dos años después.

En efecto, siguiendo las instrucciones de los monarcas, el corregidor convocó una reunión del concejo en la que, entre otras cosas, se habló de la reforma del regimiento y expuso su parecer de que, debido al número de vecinos de la ciudad, cifrado entre 1.400 y 1.500 vecinos, unas 6.750 personas, "que seria bien e serviçio de sus altezas que oviese de aver en esta çibdad numero de doze regidores e no de treynta e seys, porque la çibdad seria mejor regida e gouernada e ternian los regidores mas a la memoria las cosas de la gouernaçion desta dicha çibdad" ${ }^{30}$. De la misma opinión fueron los asistentes a la reunión, por lo menos nadie se manifestó en contra entonces, quedando el acuerdo de reducir a la docena el número de regidores. Paso siguiente fue establecer el modo de reducción y la vigencia del mandato, cosa que se acometió de inmediato, siguiendo en líneas generales la carta real de 1478, hasta que "quedados en doze regidores, que aquellos rijan para en jamas en esta dicha çibdad e rijan en tanto que biuieren ${ }^{31}$. De esta manera que-

\footnotetext{
29 Apéndice Documental VI.
}

30 1490-III-11, Loca. Pub. A. L. Molina Molina: «Las Ordenanzas...», págs. 131-132. Los regidores asistentes fueron: Martín de Cañizares, Juan García de Guevara, Alvaro Pérez de Briviesca, Juan Bravo de Morata, Gil Martínez de Pareja, Fernando de Gomariz, Juan de Guevara, Alfonso de Terual, Martín Fernández Fajardo, Juan Navarro de Alava, Alfonso Mateo, Martín Fernández Piñero, Gonzalo Piñero, Pedro Mellado, Martín de Molina, Gómez García de Alcaraz y Lope Piñero.

31 Los regidores existentes, es decir los 36 regirían la mitad de ellos un año y los otros 18 el año siguiente y así sucesivamente hasta que, dejadas las vacantes sin cubrir, se llegase a los doce. Producida una vacarite en el regimiento de ahora establecido, los 11 restantes, junto con el corregidor o alcalde, «que elijan e nonbren otro ombre bueno, abil e sufiçiente, para el dicho ofiçio, e que la heleçion sea desta manera: Que todos los regidores, en vno con el alcalde o justiçia, sean llamados e juntos a la camara del conçejo para fazer la tal eleçion, e juren sobre la señal de la cruz e los quatro Santos Evangelios, en forma deuida de derecho, e se aparte el alcalde e el escriuano de conçejo con cada vno de los dichos regidores para que diga e declare a quien le paresçe en toda la çibdad que tenga mas abilidad y sufiçiençia para el dicho ofiçio de regidor; e despues de aver jurado e votado, vean qual terna mas votos e aquel que terna mas votos sea avido e reçebido por regidor». A. L. MOLINA MOLINA: «Las Ordenanzas...», p. 132. 
daba consagrado el regimiento vitalicio, a pesar de una reacción en contra que una minoría protagonizó una semana después y cuyo resultado fue el fracaso ${ }^{32}$. Todo dependía ya de la longevidad de los $36^{33}$.

El regimiento vitalicio era ya una realidad en septiembre de 1509 , fecha en la que Adrián Leonés es designado regidor en sustitución del fallecido Martín Fernández Fajardo, por Juana I quien aceptó la propuesta realizada por el concejo ${ }^{34}$. De esta manera se consumaba el proceso de patrimonialización del cargo y la tendencia a convertirlo en hereditario, ya que, a pesar de su carácter legalmente electivo, los regidores "por defravdar la eleçion que la dicha çibdad suele hazer de lo ofiçios de regimiento quando acaeçe que vaca algund ofiçio » ${ }^{35}$, no daban lugar a que se produjese una vacante efectiva, al renunciar el cargo "secretamente" en sus hijos o en las personas que considerasen oportuno, manteniendo en secreto tales renuncias "dos o tres o quatro años e mas" para, una vez fallecido el titular, poder mostrar el documento y pedir confirmación del cargo. Para evitar esta ilegalidad, la reina fijó un plazo de 60 días para que aquel en quien fuese renunciado algún regimiento se presentase ante el concejo para que se viese la suficiencia del individuo y ser propuesto para el cargo mediante la correspondiente elección, y otros 60 para presentarla ante la reina para su confirmación.

32 La ratificación del acuerdo se produjo en una sesión extraordinaria, celebrada el miércoles siguiente. Fue una reunión tumultuosa a la que asistieron 28 de los 36 regidores: Martín de Cañizares, Juan García de Guevara, Juan Bravo de Morata, Gil Martínez de Pareja, Fernando de Gomariz, Juan Felices, Juan de Guevara, Alfonso de Teruel, Juan Fernández de Ribavellosa, el bachiller Alvaro Pérez de Briviesca, Andrés Navarro, el comendador Gómez Fajardo, Martín Fernández Fajardo, Martín Fernández Piñero, Diego López de Guevara, Martín de Molina, Gonzalo Piñero, Juan Sánchez Mellado, Pedro Tamarid, Juan García de Alcaraz, Ximén López de Guevara, Gómez García de Guevara, Pedro Mellado, Alfonso Mateo, Pedro Leonés, Lope Piñero, Juan Navarro de Santa María y Juan Bernad. Los regidores Juan Sánchez Mellado, Pedro Tamarid, Ximén López de Guevara y Juan Navarro de Santa María quienes no asistieron al concejo del día 11 en el que se adoptó el acuerdo, expusieron su disconformidad, alegando que «no consentian en la ordenança ni mudamiento del regimiento de los treynta e seys que venga en doze regidores como dizen, saluo que este el regimiento desta çibdad en treynta e seys regidores, como oy estan e syenpre fue, e que en lo al no consyenten que queden en doze regidores", a este parecer se sumó Gil Martínez de Pareja quien ahora muestra su desacuerdo a pesar de que en la reunión anterior no mostró discrepancia alguna. AML A.C. 1489-90, sesión del 17-III-1490. La ordenanza de los 12 fue rectificada sin mayores problemas.

33 Cuatro años después todavía se ordena a Gómez García Alcaraz, regidor y procurador síndico, que convocase «los treynta e seys" para el lunes, 29 de diciembre. $A M L$ A.C. 1494-95, sesión del 27-XII-1494.

34 Apéndice Documental VII.

35 1514-IV-4, Madrid. AML Libro II de Privilegios, fol. 146v-147v. 
Con todo la instauración del regimiento vitalicio no sirvió para dotar a la ciudad de un buen gobierno, no por la ordenanza en sí, sino por las personas que la ejercieron, ya que la mayor parte de las veces no eran los más capaces, sino los más influyentes los que dirigirían los destinos de la ciudad. Acaso sirvió para mantener un orden institucional y crear una unidad falsa y frágil basada en el poder económico y político de unos pocos que monopolizaban el poder poniendo freno a todo aquello que fuese contra sus intereses, lo cual distaba mucho de alinearse con la idea de unidad y buen gobierno de López de Dávalos, con la de aquellos que hasta última hora la defendieron, con las premisas que, en este mismo sentido, pregonaron los reyes por boca de Mosén Juan Cabrero, ni con las necesidades de Lorca. 


\section{APÉNDICE DOCUMENTAL}

\section{DOCUMENTO I}

1400-X-16, Toro.

Enrique III al concejo de Lorca. Confirmando el regimiento establecido en la ciudad por Ruy López de Dávalos.

(AML Cartas de Enrique III, núm. 1).

Don Enrique, por la graçia de Dios, rey de Castilla, de Leon, de Toledo, de Gallizia, de Seuilla, de Cordoua, de Murçia, de Jahen, del Algarue, de Algeriza e señor de Vizcaya e de Molina. A uos, el conçejo e alcalles e alguazil e regidores e ofiçiales e omes buenos de la mi villa de Lorca, salut e graçia.

Sepades que vi vuestras petiçiones, que me enbiastes con Pedro Ferrandez de Figueroa, vuestro vezino, entre las quales me enbiastes pedir por merçed que por quanto al tienpo que yo mande yr al regno de Murçia, por algunas cosas que conplian a mi seruiçio, a Ruy Lopez de Daualos, mi condestable, e diz quel que andouo veyendo e regiendo algunas villas e lugares del dicho regno, segunt que ge lo yo auia mandado, e diz quel que veno a esa dicha villa por la regir e que fallo que se regia por conçejos generales e que, quando los tales conçejos se fazian publicamente, que auia muchos escandalos e males, e quel ve- 
yendo que no era mi seruiçio los conçejales estar con los ofiçiales a los cabillos e conçejos, quel dicho mi condestable, que espeçifico e nonbro en esa dicha villa treynta e seys omes buenos, de los quales cada año fuesen con vuestros ofiçiales en vuestros cabillos e regimiento los seys dellos, en tal manera que cada año ouiese seys omes buenos, mudandose cada año los dichos seys omes buenos de vn año en otro, e quel dicho mi condestable que vos mando, de mi parte, que lo vsasedes asy de aqui adelante; e diz que vos, por el dicho mandamiento, que lo fazedes asi e reçibistes los dichos treynta e seys omes buenos, que vos el nonbro, e vsades con los seys dellos por vn año en los dichos vuestros cabillos e conçejos. $E$ que me pediades por merçed que vos quisiese confirmar el dicho regimiento de los dichos omes buenos, segunt el dicho mi condestable lo mando, lo qual era mi seruiçio. E yo, touelo por bien.

Por ende, yo lo confirmo en la manera quel dicho mi condestable to ordeno e mando en esa dicha villa, de los dichos treynta e seys omes buenos, e mando que vsedes con los dichos seys omes buenos dellos cada año en vuestros conçejos e regimientos, e quando los vnos seys omes buenos cunplieren su año, que tomedes otros seys omes buenos de los otros que quedan e dende adelante asi cada año, en tal manera que todos treynta e seys omes, cada seys omes buenos vn año, cunplan el dicho regimiento de vn año en otro, segunt lo el dicho mi condestable mando. $E$ defiendo e mando que ningunos ni aigunos no vayan ni pasen contra el dicho regimiento quel dicho mi condestable fizo, ni contra esta dicha confirmaçion que yo dello fago, so pena de la mi merced e de los cuerpos e de quanto auedes para la mi camara, ca yo los reçibo en mi guarda e anparo; e defiendo que ningunos ni algunos les no fagan mal ni daño ni desaguisado alguno, so la dicha pena.

Dada en Toro, diez e seys dias de Octubre, año del nasçimiento del Nuestro Señor lhesu Christo de mill e quatroçientos años. Yo, Alfonso Ruyz, la fiz escreuir por mandado de nuestro señor el rey. Chançeller. Perafan. Garçia Gonçalez. Registrada. 
DOCUMENTO II

1412-VII-29, Guadalajara.

Juan II al concejo de Lorca. Mandando que se respetase la ordenanza de Enrique III sobre el regimiento.

(AML Libro II de Privilegios, fol. 208r-209r).

Don Juan, por la graçia de Dios, rey de Castilla, de Leon, de Toledo, de Galizia, de Sevilla, de Cordova, de Murçia, de Jahen, del Algarbe, de Algezira e señor de Vizcaya e de Molyna. Al conçejo y alcaldes e alguazil e regidores e jurados e omes buenos de la villa de Lorca, e a cada vno de vos a quien esta my carta fuere mostrada, salud e graçia.

Sepades que a my es dicho e notefycado en como agora puede aver treze años, poco mas o menos tienpo, quel rey don Enrique, my señor e padre, que aya santo parayso, enbio al reyno de Murçia e a esa dicha villa a don Ruy Lopez de Davalos, my condestable, con poderio a corregir y emendar lo que fallase que no se regia ni fazia bien, segund que a su seruiçio cunplia. El qual dicho condestable diz que fue a esa dicha villa e fallo que se regia por conçejo, lo qual entendio que no hera serviçio del dicho señor rey, my padre, y que, por virtud del dicho poderio que asi llevava, que hordeno e mando que se regiese esa dicha vila por çierto numero de regidores que fuesen puestos de cada año, la qual hondenança diz que el dicho rey, my padre, veyendo que hera su serviçio, que la confyrmo e mando guardar dende en adelante; de la qual dicha hordenança diz que a vsado despues aca esa dicha villa, esleyendo de entre sy çiertos regidores e ofiçiales de cada año, por el dia de San Juan Batista. 
E diz que el dia de San Juan, que agora paso, deste año de la data desta my carta, que estando ayuntado el conçejo desa dicha villa para oyr e resçebir los ofiçials que asy eran esleydos, segund la forma de la dicha hordenança, que algunas personas desa dicha villa se alborotaron e levantaron, diziendo que no consentian que obiese regidores e que los quitasen e que se movyo gran alboroto en la dicha villa, por la dicha razón. De lo qual, sy asy es, yo so mucho maraviilado en las tales personas se atrever a fazer lo sobredicho, seyendo contra la dicha hordenança, confyrmada por el dicho rey, mi padre, como dicho es.

Porque vos mando a todos e a cada vno de vos, que de aqui adelante guardedes e cunplades la dicha hordenança e, segund el thenor della, esleyades e pongades regidores e otros ofiçiales acostunbrados, e no consyntades que alguno ny algunos se entremetan de quebrantar e mudar o contrallar la dicha hordenança por alguna manera, ca my merçed e voluntad es que se guarde e cunpla, segund que fasta aqui se aguardado e cunplido, en todo e por todo, segund el thenor della.

E los vnos e los otros no fagades ende al por alguna manera, so pena de la my merçed e de diez myll maravedis para la my camara a cada vno por quien fyncare de lo asy fazer e conplir.

Dada en la villa de Guadalfajara, beynte e nueve dias del mes de Jullio, año del nasçimiento del Nuestro Saluador Ihesu Christo de myll e quatroçientos e doze años. Yo, Gutierre Diaz, la fize escreuir por mandado e nuestro señor el rey, por quanto fue asy acordado en el su consejo. Johannes, Chançeller. Episcopus Cartaginiensis. Perafan. Registrada. 
DOCUMENTO III

1477-XI-24, Sevilla.

Reyes al concejo de Lorca. Ordenando respetar la ordenanza del regimiento y prohibiendo la reducción a 12 y su conversión en vitalicios.

(AML Libro II de Privilegios, fol. 17r-18r).

Don Fernando e doña Ysabel, por la graçia de Dios, rey e reyna de Castilla, de Leon, de Toledo, de Seçilia, de Portogal, de Galizia, de Sevilla, de Cordoua, de Murçia, de Jahen, de los Algarves, de Algezira, de Gibraltar, prinçipes de Aragon e señores de Vizcaya e de Molyna. A vos, el conçejo, alcaldes, alguaziles, regidores, caualleros, escuderos, ofiçiales e omes buenos de la çibdad de Lorca, e a cada vno e qualquier de vos a quien esta nuestra carta fuere mostrada o el traslado della, signado de escriuano publico, salud e graçia.

Sepades que, por parte de los regidores e otras personas, vezinos desa dicha çibdad, nos es fecha relaçion diziendo que, no obstante que Is dicha çibdad e vezinos della tyenen çiertos previllegios, de sus buenos vsos e costunbres, de los reyes de gloriosa memoria, nuestros progenitores, vsados e guardados, espeçialmente sobre la eleçion de los ofiçios de regimientos della, de como e en que manera cada año se an de elegir e que numero dellos a de ser, que agora, nuevamente, algunos cavalleros e personas, vezinos desa dicha çibdad, en escandalo e daño de la dicha çibdad e por se apoderar del regimiento e governaçion de la dicha çibdad, an procurado e procuran de les quebrantar los dichos sus previllegios e buenos vsos e costunbres e de fazer los dichos regimyentos 
perpetuos e que sean catorze, no lo pudiendo ny deviendo hazer; en lo qual dizen, que si oviese a pasar, que esa dicha çibdad e vezinos della reçibirian mucho agravio e daño. E nos suplicaron e pidieron por merçed, çerca dello, con remedio de justiçia, les proveyesemos, mandandoles dar nuestra carta para que los dichos previllegios e buenos vsos e costunbres, quesa dicha çibdad e vezinos della tyenen, en todo les fuesen cunplidos e guardados, o como la nuestra merçed fuese. $E$ nos, tovymoslo por bien e mandamos dar esta nuestra carta para vosotros en la dicha razon.

Por la qual vosmandamos, a todos e a cada vno de vos, que veades los dichos previllegios e buenos vsos e costunbres quesa dicha çibdad de Lorca tiene de los dichos reyes, nuestros antepasados, e sy fasta aqui aquellos an seydo e son vsados e guardados, ge los guardedes e cunplades e fagades guardar e cunplir en todo e por todo, segund que en ellos se contiene, sy e segund e por la forma e manera que fasta aqui los avedes guardado; y, en guardandolos e cunpliendolos, que eligades e nonbredes los dichos ofiçios de regimientos, sy e segund e por la forma e manera que fasta aqui lo avedes fecho, por manera que los dichos previllegios e vsos e costunbres en todo e por todo sean cunplidos e guardados.

E los vnos ny los otros no fagades ni fagan ende al por alguna manera, so pena de la nuestra merçed e de priuaçion de los ofiçios e de confiscaçion de todos vuestros bienes de los que lo contrario fizieredes para la nuestra camar; e demas mandamos al ome que vos esta nuestra carta mostrare, que vos enplaze que parescades ante nos, en la nuestra corte, do quier que seamos, del dia que vos enplazare fasta quinze dias primeros siguientes, so la dicha pena; so la qual, mandamos a qualquier escriuano publico, que para esto fuere llamado, que de ende, al que vos la mostrare, testimonio, sygnado con su sygno, porque nos sepamos en como se cunple nuestro mandado.

Dada en la muy noble e muy leal çibdad de Sevilla a veynte e quatro dias de Novienbre, año del nasçimiento de Nuestro Señor Ihesu Christo de mill e quatroçientos e setenta e syete años. Yo, el Rey. Yo, la Reyna. Yo, Gaspar de Arino, secretario del rey e reyna, nuestros señores, la fyze escrevir por su mandado. 
DOCUMENTO IV

1478-IV-3, Madrid.

Fernando $\mathrm{V}$ al concejo de Lorca. Ordenando reducir a 12 el número de regidores.

(AML Libro II de Privilegios, fol. 124r-125r).

Don Fernando, por la graçia de Dios, rey de Castilla, de Leon, de Toledo, de Seçilia, de Portugal, de Galizia, de Sevilla, de Cordoua, de Murçia, de Jahen, de los Algarves, de Algezira, de Gibraltar, prinçipe de Aragon e señor de Vizcaya e de Molina. A vos, el conçejo, alcaldes, alguaziles, regidores, jurados, cavalleros, escuderos e omes buenos de la nble çibdad de Lorca, e a cada vno de vos, salud e graçia.

Sepades que Juan Pardo, my escrivano de camara, vezino desa çibdad e procurador della y en vuestro nonbre, me fizo relaçion que, porque los ofiçios de alcaldias e alguazilazgo e regimyento e jurados e mayordomos se ponian por colaçiones, en las quales colaçiones se podian aver tales personas quales cunpliesen para my serviçio e al byen e pro comun de la dicha çibdad e ponyan de los que fallavan entre ellos; e asy mesmo, diz que ay grand numero de regidores en la dicha çibdad. E que si yo en todo ello no proveyese como cunpliese a mi serviçio, la dicha çibdad resçibiria gran daño e no seria byen regida.

Por ende, yo, como rey e señor, queriendo proveer en ello como entiendo que es cunplidero a mi serviçio e al byen e pro comun desa 
çibdad, mi merçed e voluntad es que los regimientos que son vacos e de aqui adelante vacaren de los treynta e seys regidores que oy son en esa çibdad, se consuman e queden consumydos, e yo, por esta mi carta, los consumo fasta que queden e sean en numero de doze regidores e no mas. E sy, asy reduzidos el dicho numero de los dichos doze regidores, acaesçiere que alguno dellos vacare, que los otros honze regidores, en vno con vos, la dicha justiçia e procurador e mayordomo desa dicha çibdad, elijades por el cuerpo della dos buenas personas para el dicho ofiçio de regimiento e aquellos dos hechen suertes, e al que cayere, mando e es mi merçed, que aya el ofiçio e bienes del. E asy mesmo, mando que, cada que se oviere e poner en esa çibdad alcaldes e alguazil, jurados e mayordomo, se tomen e elijan por vos, los dichos regidores, de todo el cuerpo desa çibdad e no por parrochas, tomando para cada ofiçio dos buenas personas e echen suertes en la forma susodicha.

Porque vos mando, a todos e a cada vno de vos, que lo guardedes e cunplades asy e no vayades ny consyntades yr contra ello, e vos, los dichos omes buenos e vezinos desa çibdad, dedes e fagades dar todo el favor e ayuda a vos, las dichas justiçias e regidores, e mando que esto se guarde del dia que los dichos ofiçios fuesen consumidos en adelante. E mando a todas las justiçias, asy hordinarias como de la Hermandad, que den e fagan dar todo el favor e ayuda que les pidieredes e menester ovieredes, e que vos non pongan ny consientan poner en ello, ni en parte dello, enbargo ny contrario alguno. Pero sy contra lo que dicho es o contra qualquier cosa dello, alguna persona o personas se syntieren dello agraviados, yo les mando que parezcan ante my, en el mi consejo, porque yo les mande oyr e se faga sobre ello lo que sea justiçia.

E los vnos ny los otros no fagades ni fagan ende al, so pena de la mi merçed e de privaçion de los ofiçios e de confiscaion de los bienes de los que lo contrario fyzieredes o fyzieren para la mi camara; e demas, mando al ome que vos esta mi carta mostrare, que vos enplaze que parezcades ante $\mathrm{mi}$, en la mi corte, del dia que vos enplazare fasta quinze dias primeros siguients, so la qual dicha pena mando a qualquier escriuano publico, que para esto fuere llamado, que de ende, al que vos la mostrare, testimonio, signado con su signo, porque yo sepa en como se cunple my mandado.

Dada en Madrid, tres dias de Abril, año del nasçimiento de Nuestro Saluador Ihesu Christo de mill e quatroçiêntos e setenta e ocho años. Yo, el Rey. Yo, Gaspar de Arino, secretario del rey, nuestro señor, la fyz escreuir por su mandado. 
DOCUMENTO $V$

1479-VI-5, Trujillo.

Reyes al concejo de Lorca. Ordenando guardar la ordenanza del regimiento y revocando todas aquellas cartas que habian dado en contra de la misma.

(AML Libro II de Privilegios, fol. 120r-122v).

Don Fernando e doña Ysabel, por la graçia de Dios, rey e reyna de Castilla, de Leon, de Aragon, de Seçilia, de Toledo, de Valençia, de Portugal, de Galizia, de Sevilla, de Mallorcas, de Çerdenia, de Cordova, de Corçega, de Murçia, de Jahen, de los Algarves, de Algezira, de Gibraltar, conde e condesa de Barçelona, señores de Vizcaya e de Molyna, duques de Athenas e de Neopatria, condes de Rosellon e de Çerdania, marqueses de Oristan e de Goçiano. A vos, el conçejo, regidores, cavalleros, escuderos, ofiçiales e omes buenos de la çibdad de Lorca, e a cada vno de vos a quien esta nuestra carta fuere mostrada o su traslado, signado de escrivano publico, salud e graçia.

Sepades que por parte de algunos regidores de la dicha çibdad nos es fecha relaçion diziendo que nos, estando en la muy noble çibdad de Sevilla, nos hizieron saber como otros algunos regidores desa dicha çibdad yntentavan quebrantar los buenos vsos e costunbres della, queriendo mudar en otra sustançia los ofiçios de alcaldes e alguaziladgo e regimientos e otros ofiçios, asy reales como conçegiles, en quebrantamiento de los dichos previllegios e buenos vsos e costunbres, que de luengos tienpos a esta parte fueron vsados e guardados. Sobre lo qual, nos avia- 
mos mandado dar e dymos vna nuestra carta, fyrmada de nuestros nonbres e sellada con nuestro sello, para que los dichos previllegios e buenos vsos e costunbres que esa dicha çibdad tiene de los reyes de gloriosa memoria, nuestros progenitores, fuesen vsados e guardados e cunplidos en todo e por todo, e para que, segund el thenor e forma dellos, pudiesedes elegir e nonbrar los dichos ofiçios.

E despues, estando yo, el rey, en la villa de Madrid, a suplicaçion de los dichos regidores que yntentaron quebrantar los dichos previllegios e buenos vsos e costunbres antiguas, con relaçion no verdadera que sobre ello me fyzieron, mande dar e di vna my carta sobre la eleçion de los dichos ofiçios en çierta forma, mudando la sustançia de los dichos privillegios e buenos vsos e costunbres antiguas, contra la qual dicha carta de my, el rey, los dichos regidores se opusieron diziendo, por vna petiçion que en el nuestro consejo presentaron, que hera en gran daño e perjuyzio de la dicha çibdad e de los dichos previllegios e buenos vsos e costunbres antiguas della, e que por cabsa dello estaban aparejados grandes escandalos para la primera eleçion que se avya de hazer de los dichos ofiçios. Por ende, que vnos suplicavan e pedian por merçed que mandasemos dar nuestra carta para que los dichos ofiçios fuesen dados y elegidos por colaçiones, segund el thenor e forma de los dichos preuillegios antiguos e segund que de luengo tienpo aca, que memoria de honbres no es en contrario, se avya vsado; sobre lo qual, asy mysmo, los dichos regidores que yntentavan quebrantar los dichos previllegios, mostraron ante nos, en el nuestro consejo, la dicha carta que yo, el rey, mande dar en la dicha villa de Madrid, e otras escripturas, e nos suplicaron e pydieron por merçed que mandasemos ver el conplimiento de la dicha carta de $\mathrm{mi}$, el rey, e lo que por virtud della se avya fecho, e aquella aprovasemos e confirmasemos para que valiese e oviese devido efecto agora e de aqui adelante, perpetuamente para sienpre jamas, segund y en la manera que en la dicha nuestra carta, orden e determynaçion se conthenia. $\mathrm{E}$ vistas por los del nuestro consejo las dichas cartas e escrituras por amas, las dichas partes, ante nos traydas e presentadas, e asy mismo lo allegado por ellos por las dichas sus petiçiones, fue acordado que nos deviamos mandar dar esta nuestra carta para vosotros en la dicha razon. E nos, tovymosio por bien.

Porque vos mandamos, a todos e a cada vno de vos, que veades los dichos previllegios e buenos vsos e costunbres quesa dicha çibdad de Lorca tiene de los dichos reyes, nuestros progenitores, en quanto a la eleçion e nonbramiento de los dichos ofiçios, e los guardedes e cunplades e fagades guardar e cunplir, agora e de aqui adelante, en todo e por 
todo, segunde por la forma e manera que en ellos y en cada vno dellos se contiene, sy e segund que fasta aqui los avedes vsado e guardado e conplido; e, en cunpliendolos e guardandolos, elides e nonbredes los dichos ofiçios, segund e por la forma e manera que fasta aqui lo avedes fecho, por manera que, los dichos previllegios e vsos e costunbres antiguos, en todo e por todo sean cunplidos e guardados. Ca, nos, por esta dicha nuestra carta, rebocamos e anulamos qualquier carta que en contrario de los dichos previllegios e vsos e costunbres antiguos ayamos dado.

E por quanto a nos es fecha relaçion que las collaçiones de San Pedro e San Clemente de la dicha çibdad, por ser tan pequeñas e de tan pocos vezinos, no ay en ellas copio de tantas personas como ay en cada vna de las otras collaçiones para concurrir en la dicha eleçion e nonbramiento de los dichos ofiçios. Por ende, es nuestra merçed e voluntad, e por esta dicha nuestra carta mandamos que, de aqui adelante, las dichas collaçiones de San Pedro e San Clemente sean avidas por vna collaçion en quanto atañe o atañare a la dicha eleçion de los dichos ofiçios, e que los dichos ofiçios se repartan en las dichas dos collaçiones por las personas dellas, segund e por la forma e manera que en cada vna de las otras çinco colaçiones se reparten e acostunbran repartir.

E los vnos ny los otros no fagades ende al por alguna manera, so pena de la nuestra merçed e de diez mill maravedis para la nuestra: camara a cada vno de vos, por quien fyncare de lo asy fazer e cunplir, e de privaçion de los ofiçios e de confiscaçion de los bienes; e demas, mandamos al ome que vos esta nuestra carta mostrare, que vos enplaze que parezcades ante nos, en la nuestra corte, do quier que nos seamos, del dia que vos enplazare fasta quinze dias primeros siguientes, so la dicha pena; so la qual mandamos a qualquier escriuano publico, que para esto fuere llamado, que de ende, al que vos la mostrare, testimonio, signado con su signo, porque nos sepamos en como se cunple nuestro mandado.

Dada en la noble çibdad de Truxillo a quatro dias de Junio, año del nasçimiento de Nuestro Salvador Ihesu Christo de mill e quatroçientos e setenta e nueve años. Va escripto sobre raydo e o diz cunplido, vala. Yo, el Rey. Yo, la Reyna. Yo, Johan Ruyz del Castillo, secretario del rey e de la reyna, nuestros señores, la fize escreuir por su mandado. Garçi Ferrandez Manrique. Rodericus, dotor. Andres, dotor. Johannes, dotor. Registrada. Alfonso Ximenez. Diego Vazquez, Chançeller. 
DOCUMENTO VI

1488-VII-6, Murcia.

Isabel I al corregidor de Lorca. Ordenando que le informase sobre la conveniencia de que en la dicha ciudad se eligiesen 12 regidores en cada año en lugar de los seis establecidos en la ordenanza del regimiento.

(AML Libro II de Privilegios, fol. 131v-132r).

Doña Ysabel, por la graçia de Dios, reyna de Castilla, de Leon, de Aragon, de Seçilia, de Toledo, de Valençia, de Galizia, de Mallorcas, de Sevilla, de Çerdenya, de Cordoua, de Corçega, de Murçia, de Jahen, del Algarve, de Algezira, de Gibraltar, condesa de Barcelona e señora de Vizcaya e de Molina, duquesa de Atenas e de Neopatria, condesa de Ruysellon e de Çerdanya, marquesa de Oristan e de Goçiano. A vos, el mi corregidor de la çibdad de Lorca, salud e graçia.

Sepades quel conçejo, cavalleros, escuderos, ofiçiales e omes buenos de la dicha çibdad de Lorca, me enbiaron fazer relaçion por su petiçion, que ante $\mathrm{mi}$, en el mi consejo, presentaron, diziendo que esta de costunbre que en cada parrochia eligen vn regidor e destas seys personas toman de cada collaçion vna, que son de seys collaçiones seys personas, los quales tyenen cargo de regir vn año, y en pos de aquellos, otro año siguiente, otros seys hasta que se acaba el numèro de las dichas seys personas de cada collaçion, e acabadas tornan a hazer otra eleçion en la forma susodicha. $E$ que por cabsa que los dichos seys regidores son de todos los estados de la dicha çibdad e muchas vezes 
acaesçe que la mayor parte de los regidores van a entender en sus haziendas y en otras cosas fuera de la dicha çibdad, por manera que en la dicha çibdad quedan muy pocos regidores para la regir y que, por cabsa desto, avian fecho vna hordenança que, como regian en la dicha çibdad cada año seys regidores, rigesen doze. La qual dicha hordenança me suplicavan e pedian por merçed mandase confirmar.

Lo qual, visto en el mi consejo, fue acordado que devia mandara vos que oviesedes ynformaçion qual hera mas nesçesario a mi serviçio eal bien e vtilidad de la dicha çibdad, que oviese en ella los dichos seys regidores cada año o los dichos doze. La qual dicha informaçion vos ovistes e, porque por ella paresçe que diz que es nesçesario que aya en la dicha çibdad mayor numero de regidores que los dichos seys, mande dar esta my carta para vos en la dicha razon.

Por la qual vos mando que veays que numero de regidores son menester de los que asy estan elegidos en las dichas collaçiones, para que la dicha çibdad este bien regida e gobernada, y el numero que vos declararedes que asy es menester, yo, por la presente, lo declaro asy, tanto que non suba de mas ny allende de los dichos doze regidores. El qual dicho numero de regidores que asy declararedes ques menester para regir bien la dicha çibdad, yo, por la presente les mando que vsen de los dichos ofiçios en todo lo a ellos conçerniente e ayan e lleven los derechos e salarios a los dichos ofiçios anexos e pertenesçientes, segund e como lo vsavan e avian e llevavan los dichos seys regidores, e non de mas ni allende.

E non fagades ende al por alguna manera, so pena de la mi merçed e de diez mill maravedis para la my camara; e demas, mando al ome, que vos esta mi carta mostrare, que vos enplaze que parezcades ante my, en la my corte, do quier que yo sea, del dia que vos enplzare en quinze dias primeros siguientes, so la dicha pena; so la qual, mando a qualquier escrivano publico, que para esto fuere llamado, que de ende, al que vos la mostrare, testimonio, signado con su signo, porque yo sepa en como se cunple my mandado.

Dada en la çibdad de Murçia a seys dias del mes de Jullio, año del nasçimiento de Nuestro Señor Ihesu Christo de mill e quatroçientos e ochenta e ocho años. Va escripto sobre raydo o diz vn regidor e o diz seys en dos lugares, vala. Yo, la Reyna. Yo, Fernand Alvarez de Toledo, secretario de nuestra señera, la reyna, la fize escreuir por su mandado. 
DOCUMENTO VII

1509-IX-28, Valladolid.

Juana I al concejo de Lorca. Notificando el nombramiento de Adrián Leonés como regidor vitalicio en sustitución del fallecido Martín Fernández Fajardo.

(AML Libro II de Privilegios, fol. 143r-144v).

Doña Juana, por la graçia de Dios, reyna de Castilla, de Leon, de Granada, de Toledo, de Galizia, de Sevilla, de Cordoua, de Murçia, de Jahen, de los Algarues, de Algezira, de Gibraltar, de las yslas de Canaria e de las Yndias, yslas e tierra fyrme del mar oçeano, prinçesa de Aragon e de las Dos Seçilias, de Jherusalem, archiduquesa de Avstris, duquesa de Borgoña e de Brauante, etc., condesa de Flandes e de Tirol, etc., e señora de Vizcaya e de Molyna, etc... A vos, el conçejo, justiçia, regidores, caualleros, escuderos, ofiçiales eomes buenos de la çibdad de Lorca, alud e graçia.

Sepades que vi vuestra petiçion, que me embiastes, en que me faziades saber que Martin Ferrandez Fajardo, regidor que fue de la dicha çibdad de Lorca, hera fallesçido e pasado desta presente vida, e que vos, conformando vos con vuestros previllegios e vso e costunbre que theneys de elegir e nonbrar los tales regidores, elegistes e nonbrastes en su lugar del dicho Martin Ferrandez Fajardo, para el dicho ofiçio de regimiento, a Adrian Leones, vezino de la dicha, e que me suplicavades e pediades por merçed vos mandase confyrmar la dicha eleçion. 
Lo qual, visto en el my consejo e con el rey, my señor e padre, consultado, fue acordado que devya mandar confyrmar la dicha eleçion por vos fecha del dicho regimiento. $E$ yo, tovelo por bien.

E por la presente, sy asy es que a vos pertenesçe la eleçion e a my la confirmaçion, por hazer bien e merçed al dicho Adrian Leones, acatando su sufiçiençia e abylidad e los serviçios que me aveys fecho e fareys de aqui adelante y en alguna emienda e remuneraçion dellos, y entendiendo que asy cunple a my seruiçio e al buen regimiento desa dicha çibdad, es my merçed que, agora e de aqui adelante para en toda su vida, sea my regidor de la dicha çibdad de Lorca, en lugar e por vacaçion del dicho Martin Herrandez Fajardo, e que, asy como my regidor de la dicha çibdad, pueda gozar e goze de todas las franquezas e libertades que por razon del dicho ofiçio de regimiento deve gozar e le deven ser guardadas, e pueda llevar e lleve los derechos e salarios al dicho ofiçio pertenesçientes, como los otros regidores de la dicha çibdad deven gozar los derechos.

$E$, por esta my carta, vos mando que, luego que con ella fueredes requeridos, sin otra luenga, ny tardança, ni escusa e sin sobre ello me mas requerir ny consultar, ny esperar, ny atender otra mi carta ni mandamiento, ni segunda ny terçera insyon, juntos en vuestro cabildo e ayuntamiento, segund que lo aveys de vso e de costunbre, resçibays del dicho Adrian Leones el juramento e solenydad que en tal caso se suele e deve fazer, el qual por el fecho, le ayays e resçibays por my regidor de la dicha çibdad de Lorca, en lugar e por vacaçion del dicho Martin Herrandez Fajardo, e vseys en vno el dicho ofiçio de regimiento con el dicho Adrian Leones e le guardedes e fagades guardar todas las franquezas e libertades y exsençiones, preheminençias e prerrogativas e nmunydades que por razon del dicho ofiçio deve gozar e le deven ser guardadas, e que le acudays e fagays acudir con todos los derechos e salarios al dicho ofiçio de regimiento anexos e pertenesçientes e que por razon del deve aver e gozar e llevar, segund que, mejor e mas conplidamente, fueron guardadas e fue recudido al dicho Martin Herrandez Fajardo, e recudis a cada vno de los otros regidores de la dicha çibdad, de todo, byen e conplidamente, en guisa que le non mengue ende cosa alguna. Que yo, por la presente, le resçibo y he por resçebido al dicho ofiçio de regimiento e al vso y exerçiçio del e le doy la posesion del e poder e facultad para lo vsar y exerçer, caso que por vos, el dicho conçejo, justiçia e regidores de la dicha çibdad de Lorca, o por alguno de vos no sea resçebido. La qual dicha merçed le fago con tanto quel dicho 
regimiento no sea de los acreçentados, que se deven consumir, segund la ley fecha en las Cortes de Toledo.

E los vnos ny los otros no fagades ni fagan ende al por alguna manera, so pena de la my merçed e de diez mill maravedis para la mi camara; e demas, mando al ome, que vos esta micarta mostrare, que vos enplaze que parezcades ante my, en la my corte, do quyer que yo sea, el dia que vos enplazare fasta quinze dias primeros siguientes, so la dicha pena; so la qual, mando a qualquier escriuano publico, que para esto fuere llamado, que de ende, al que vos la mostrare, testimonio, sygnado con su signo, porque yo sepa en como se cunple my mandado.

Dada en la villa de Valladolid a veynte e ocho dias del mes de Setienbre, año del nasçimiento de Nuestro Salvador Ihesu Christo de mill e quinientos e nueve años. Yo, el Rey. Yo, Juan Ruyz de Calçeran, secretario de la reyna, nuestra señora, la fyze escreuir por mandado del señor rey, su padre. 